\title{
Androgen receptor antagonism drives cytochrome P450 17A1 inhibitor efficacy in prostate cancer
}

\author{
John D. Norris, ${ }^{1}$ Stephanie J. Ellison, ${ }^{1}$ Jennifer G. Baker, ${ }^{1}$ David B. Stagg, ${ }^{1}$ Suzanne E. Wardell, ${ }^{1}$ Sunghee Park, ${ }^{1}$ Holly M. Alley, ${ }^{1}$ \\ Robert M. Baldi, ${ }^{1}$ Alexander Yllanes, ${ }^{1}$ Kaitlyn J. Andreano, ${ }^{1}$ James P. Stice, ${ }^{1}$ Scott A. Lawrence, ${ }^{1}$ Joel R. Eisner, ${ }^{2}$ Douglas K. Price, ${ }^{3}$ \\ William R. Moore, ${ }^{2}$ William D. Figg, ${ }^{3}$ and Donald P. McDonnell'
}

'Department of Pharmacology and Cancer Biology, Duke University School of Medicine, Durham, North Carolina, USA. ${ }^{2}$ Innocrin Pharmaceuticals Inc., Durham, North Carolina, USA. ${ }^{3}$ Genitourinary Malignancies Branch, National Cancer Institute (NCI), NIH, Bethesda, Maryland, USA.

\begin{abstract}
The clinical utility of inhibiting cytochrome P450 17A1 (CYP17), a cytochrome p450 enzyme that is required for the production of androgens, has been exemplified by the approval of abiraterone for the treatment of castration-resistant prostate cancer (CRPC). Recently, however, it has been reported that CYP17 inhibitors can interact directly with the androgen receptor (AR). A phase I study recently reported that seviteronel, a CYP17 lyase-selective inhibitor, ædemonstrated a sustained reduction in prostate-specific antigen in a patient with CRPC, and another study showed seviteronel's direct effects on AR function. This suggested that seviteronel may have therapeutically relevant activities in addition to its ability to inhibit androgen production. Here, we have demonstrated that CYP17 inhibitors, with the exception of orteronel, can function as competitive AR antagonists. Conformational profiling revealed that the CYP17 inhibitor-bound AR adopted a conformation that resembled the unliganded AR (apo-AR), precluding nuclear localization and DNA binding. Further, we observed that seviteronel and abiraterone inhibited the growth of tumor xenografts expressing the clinically relevant mutation AR-F876L and that this activity could be attributed entirely to competitive AR antagonism. The results of this study suggest that the ability of CYP17 inhibitors to directly antagonize the AR may contribute to their clinical efficacy in CRPC.
\end{abstract}

\section{Introduction}

Prostate cancer is the most common cancer diagnosed in men in the United States and the second-leading cause of cancerrelated deaths (1). It is well established that prostate tumors rely on androgen signaling, via the androgen receptor (AR), to regulate the expression of genes required for cancer cell growth and survival. Thus, for patients with advanced prostate cancer, disruption of this pathway by reducing testicular androgen production with luteinizing hormone-releasing hormone (LHRH) agonists and/or prevention of AR activation with antiandrogens remain frontline therapeutic interventions (2). Although the majority of patients with prostate cancer initially respond to hormone therapy, relapse invariably occurs, and the disease progresses to a state defined as castration-resistant prostate cancer (CRPC). CRPC is associated with poor survival rates, with patients usually succumbing to metastatic disease within 24 to 48 months (3).

Despite the ability to suppress and maintain low androgen levels, it is now clear that the AR is transcriptionally active and a signif-

Authorship note: J.D. Norris and S.J. Ellison contributed equally to this work. Note regarding evaluation of this manuscript: Manuscripts authored by scientists associated with Duke University, The University of North Carolina at Chapel Hill, Duke-NUS, and the Sanford-Burnham Medical Research Institute are handled not by members of the editorial board but rather by the science editors, who consult with selected external editors and reviewers.

Conflict of interest: J.R. Eisner and W.R. Moore are compensated employees of Innocrin Pharmaceuticals Inc. J.D. Norris is a past consultant for Innocrin Pharmaceuticals Inc.

Submitted: March 1, 2016; Accepted: March 2, 2017.

Reference information: J Clin Invest. 2017;127(6):2326-2338.

https://doi.org/10.1172/JCl87328 icant driver in CRPC. This has been attributed in different scenarios to intratumoral production of androgens, overexpression of the $\mathrm{AR}$, growth factor-dependent activation of the AR, or emergence of treatment-resistant AR mutants (4-7). Therefore, even in CRPC, the $\mathrm{AR}$ and the AR-signaling axis remain important therapeutic targets. This is evidenced by the clinical efficacy of the approved hormone therapeutics enzalutamide and abiraterone in both chemotherapynaive and prior chemotherapy-treated CRPC patients $(3,8-10)$. Enzalutamide is a second-generation antiandrogen that, unlike first-generation antiandrogens (e.g., flutamide and bicalutamide), prevents the recruitment of the AR to target gene promoters and functions as an antagonist, even in the presence of AR overexpression (11). Abiraterone, on the other hand, belongs to a class of compounds known as CYP17A1 (CYP17) inhibitors that block testicular, adrenal, and intratumoral androgen synthesis (12).

The cytochrome P450 17A1 enzyme CYP17 converts the 21-carbon-containing pregnenolone and progesterone to 19carbon dehydroepiandrosterone (DHEA) and androstenedione, substrates for testosterone synthesis, through its sequential $17 \alpha$-hydroxylase and 17,20-lyase catalytic functions (13). Abiraterone is a potent inhibitor of both the hydroxylase and lyase activities of CYP17 (14). In addition to affecting androgen synthesis, inhibition of the hydroxylase activity of CYP17 leads to a reduction in cortisol production and a consequent rise in adrenocorticotrophic hormone (ACTH) and increased mineralocorticoid production, requiring coadministration of glucocorticoids with abiraterone treatment (15). More recently identified CYP17 inhibitors, such as seviteronel, galeterone (TOK-001), and orteronel (TAK-700), were developed with the hypothesis that selec- 
tive inhibition of CYP17 lyase activity could negate the need for concomitant administration of glucocorticoids by sparing CYP17 hydroxylase activity (16-18).

As with other hormone therapies, resistance to enzalutamide and abiraterone in CRPC is an impediment to a durable clinical response. The most recent studies have attributed such resistance to continued AR overexpression, increased adrenal or intratumoral androgen synthesis, expression of constitutively active AR splice variants (AR-V7), glucocorticoid receptor (GR) expression, and AR mutations $(5,19-22)$. AR point mutations are rare in early, untreated prostate tumors but commonly arise in treated CRPC tumors (23). These mutations occur most frequently in the AR ligand-binding domain (LBD) and lead to altered ligand pharmacology, such that antiandrogens function as agonists and drive the outgrowth of cells expressing the gain-of-function resistance mutation. Examples of clinically relevant mutations include T877A, W741C, and F876L, which are found in prostate tumors resistant to flutamide, bicalutamide, and enzalutamide/ ARN-509, respectively $(6,21,24-27)$. T877A mutations have also recently been identified in tumor biopsies and circulating cell-free DNA from patients with CRPC progressing on, or previously treated with, abiraterone $(21,28,29)$.

Notwithstanding the complex on-target activities of existing CYP17 inhibitors, there is evidence that these compounds may also have significant off-target activities functioning as direct inhibitors of AR transcriptional activity. In particular, galeterone has been reported to decrease AR activity in part through a mechanism that involves degradation of the receptor $(16,30-33)$. Abiraterone and its metabolite, D4A, have also been suggested to directly inhibit AR activity and impact AR protein levels, but results have varied across studies, and the clinical relevance of D4A has yet to be established (16, 31-36). Seviteronel, a CYP17 lyase-selective inhibitor, was also recently reported to have direct effects on AR function, although the molecular basis for this activity was not determined (37). The studies presented herein evaluated the potential AR antagonist activity of clinically relevant CYP17 inhibitors and attribute the importance of this secondary activity to the clinical efficacy of these inhibitors in cellular and animal models of prostate cancer. Among the most important findings from this work is the observation that the ability of seviteronel and abiraterone to inhibit CYP17 is dispensable for their antitumor activity on enzalutamide-resistant AR-F876L xenografts, suggesting that direct AR inhibition by this class of drugs probably contributes to their therapeutic efficacy.

\section{Results}

CYP17 inhibitors directly bind and antagonize AR activity. A recent study reported that an exceptional responder in a phase I study of the lyase-selective CYP17 inhibitor seviteronel for patients with CRPC demonstrated a highly durable decrease in prostatespecific antigen (PSA) levels. Biochemical data were also presented that showed direct effects of seviteronel on the AR, suggesting that the clinical response was more complex than previously expected and could be due to CYP17 lyase activity, AR antagonism, or both (37). This clinical example prompted evaluation of the effects of seviteronel and additional CYP17 inhibitors on AR activity. The ability of structurally distinct CYP17 inhibitors (Fig- ure 1A) to interact with and competitively inhibit agonist binding to the AR was assessed using a whole-cell radioligand-binding assay. Using this approach, we determined that the CYP17 inhibitors seviteronel, galeterone, abiraterone, and ketoconazole displaced $\left[{ }^{3} \mathrm{H}\right]-\mathrm{R} 1881$ (a synthetic AR agonist) from the receptor, displaying $\mathrm{IC}_{50}$ values of $4.86 \times 10^{-6}, 5.46 \times 10^{-7}, 7.60 \times 10^{-6}$, and $1.76 \times$ $10^{-4}$, respectively, while orteronel did not bind the receptor (Figure 1B). In comparison, the benchmark antiandrogens enzalutamide, bicalutamide, and hydroxyflutamide effectively displaced $\left[{ }^{3} \mathrm{H}\right]$ $\mathrm{R} 1881$, with $\mathrm{IC}_{50}$ values of $4.21 \times 10^{-7}, 1.31 \times 10^{-6}$, and $2.07 \times 10^{-7}$.

We next assessed the ability of CYP17 inhibitors to affect AR transcription in an androgen-responsive reporter gene assay (MMTV-luciferase, or MMTV-Luc) in CV1 cells (Figure 1C), which, when transfected with an AR expression construct, produced receptor levels similar to those expressed in the VCAP and LNCaP prostate cancer cell lines (Supplemental Figure 1A; supplemental material available online with this article; https:// doi.org/10.1172/JCI87328DS1). Seviteronel, galeterone, abiraterone, and ketoconazole inhibited androgen-mediated luciferase expression, with $\mathrm{IC}_{50}$ values of $1.00 \times 10^{-5}, 7.65 \times 10^{-7}, 9.42$ $\times 10^{-6}$, and $8.40 \times 10^{-5}$, respectively; because of its low potency and limiting clinical toxicities, ketoconazole was not analyzed further $(38,39)$. In agreement with the results of the binding assay, we found that orteronel failed to demonstrate any direct AR antagonism, even at concentrations of up to $100 \mu \mathrm{M}$. Enzalutamide and bicalutamide inhibited AR transcription in this assay, with $\mathrm{IC}_{50}$ values of $3.66 \times 10^{-7}$ and $1.18 \times 10^{-7}$, respectively. Hydroxyflutamide showed agonism in this model, which others have reported in the context of high AR expression (4). In addition to $M M T V$-Luc, we confirmed the AR antagonist activity of CYP17 inhibitors on the androgen-responsive PSA luciferase reporter gene (PSA-Luc) (Supplemental Figure 1B). Furthermore, we performed a Schild assay to confirm that seviteronel, galeterone, and abiraterone were competitive AR antagonists (Supplemental Figure 2). When tested for their ability to affect the transcriptional activity of related nuclear steroid receptors, seviteronel, galeterone, and abiraterone were all found to be equally efficacious progesterone receptor antagonists, with abiraterone displaying the highest potency $\left(\mathrm{IC}_{50} 2.1\right.$ $\left.\times 10^{-7}\right)$. Under the conditions of our assays, the CYP17 inhibitors tested did not impact glucocorticoid or mineralocorticoid receptor function (Supplemental Table 1).

Given the ability of seviteronel, galeterone, and abiraterone to directly antagonize AR reporter gene activity, we next assessed their capacity to regulate endogenous AR target gene expression. When tested for their ability to induce the expression of 18 well-characterized AR target genes in LNCaP cells, which express the AR-T877A mutation, we observed no significant AR agonist activity with CYP17 inhibitor treatment (Figure 1D). However, seviteronel was found to be as effective as enzalutamide in preventing androgen-mediated target gene expression (Figure $1 \mathrm{E})$, while galeterone and abiraterone were less effective on a subset of AR target genes (e.g., N-Myc downstream-regulated 1 [NDRG1], diazepam-binding inhibitor, acyl-CoA-binding protein $[D B I]$, and hydroxyprostaglandin dehydrogenase 15-(NAD) $[H P G D])$, likely reflecting their lower binding affinity for the T877A mutation. Individual graphs for the kallikrein-related pep- 
A<smiles>CC1CCC2C(CCC3(C)C(O)CCC23)C1</smiles>

Testosterone<smiles>CC1(O)CCC2C3CCC4CC(=O)CCC4C3CCC21</smiles>

R1881<smiles>CNC(=O)C1CCC(N2C(=S)N(C3CCC(C#N)C(C(F)(F)F)C3)C(O)C2(C)C(=O)O)CC1F</smiles>

Enzalutamide<smiles>N#C[C@H]1CCC(NC(=O)C(O)(O)CS(=O)(=O)C2CCC(F)CC2)CC1C(F)(F)F</smiles>

Bicalutamide<smiles>CC(C)(O)C(=O)NC1CCC([N+](=O)[O-])C(C(F)(F)F)C1</smiles>

Hydroxyflutamide

CYP17 inhibitors<smiles>CC1CN2CNC1C2C1(O)CCC2CC(OC(F)F)C(OC(F)F)CC2C1</smiles>

Seviteronel

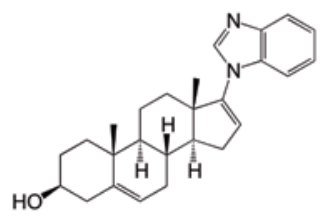

Galeterone

B

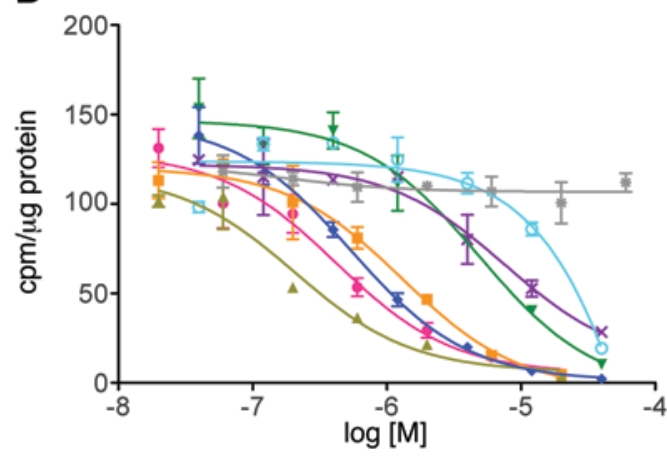

$\rightarrow$ Enz $\left(4.21 \times 10^{-7}\right) \rightarrow$ Gal $\left(5.46 \times 10^{-7}\right)$

- Bic $\left(1.31 \times 10^{-6}\right) \quad *$ Abi $\left(7.60 \times 10^{-6}\right)$

- OHF $\left(2.07 \times 10^{-7}\right) \rightarrow$ Ort $(>60 \mu \mathrm{M})$

$\rightarrow-$ Sevi $\left(4.86 \times 10^{-6}\right)-\theta$ Ket $\left(1.76 \times 10^{-4}\right)$

D
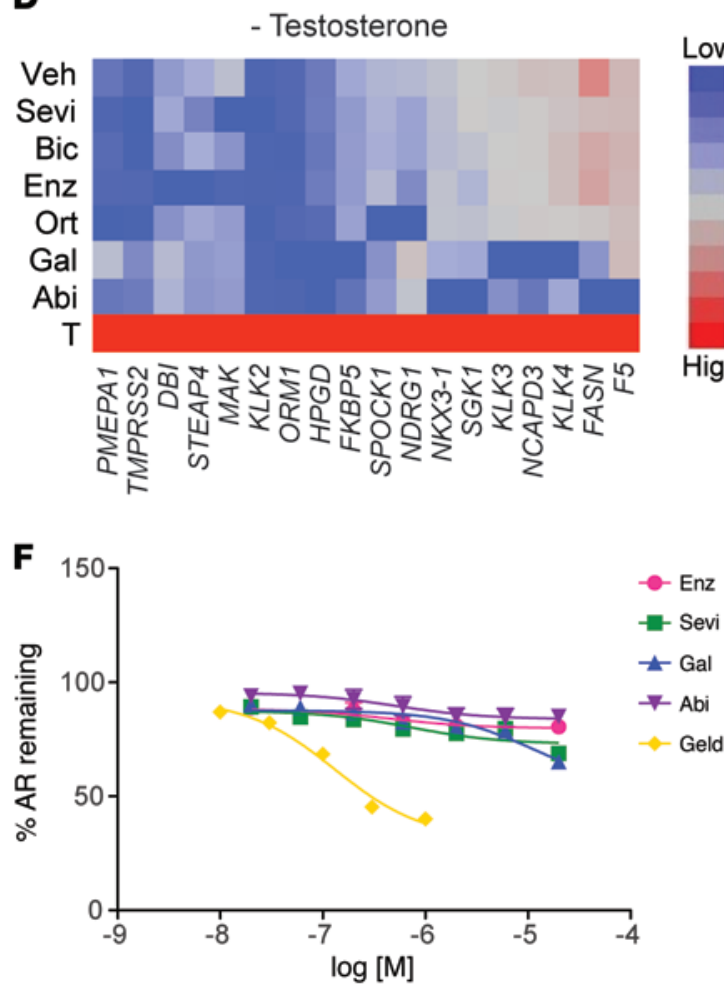

Low

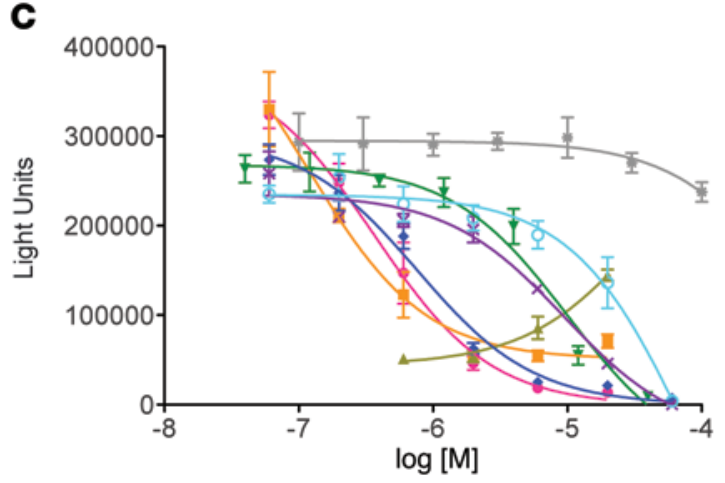

$\rightarrow$ Enz $\left(3.66 \times 10^{-7}\right) \rightarrow$ Gal $\left(7.65 \times 10^{-7}\right)$

$=$ Bic $\left(1.18 \times 10^{-7}\right) \quad *$ Abi $\left(9.42 \times 10^{-6}\right)$

$\neq$ OHF $\left(3.89 \times 10^{-5}\right)=$ Ort $(>100 \mu \mathrm{M})$

$\rightarrow$ Sevi $\left(1.00 \times 10^{-5}\right){ }^{-}$Ket $\left(8.40 \times 10^{-5}\right)$

E

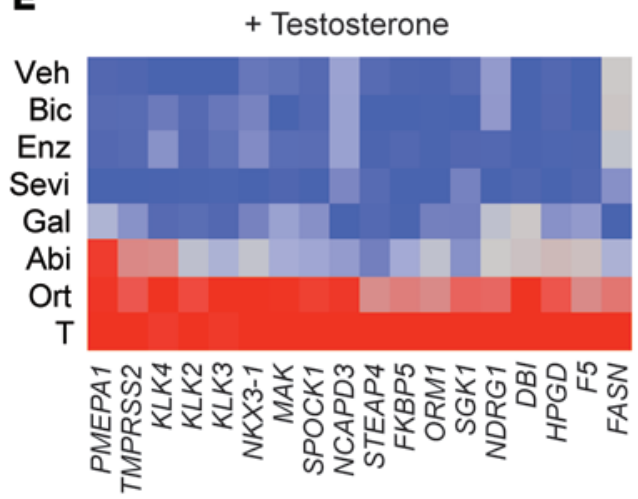

G

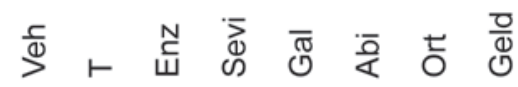

AR
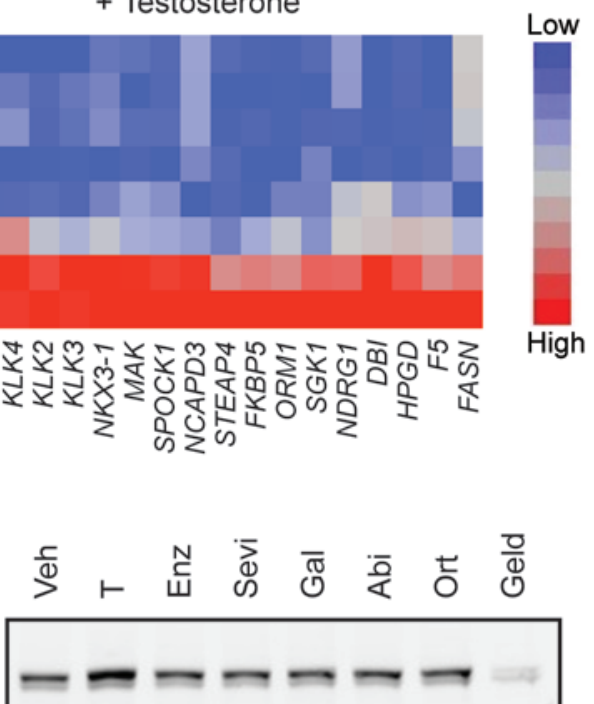

High 
Figure 1. CYP17 inhibitors bind and inhibit AR transcriptional activity. (A) Structures of the compounds used in this study, including androgens (testosterone and R1881), benchmark antiandrogens (enzalutamide, bicalutamide, and hydroxyflutamide) and CYP17 inhibitors (seviteronel, galeterone, abiraterone, orteronel, and ketoconazole). (B) HEK293 cells were transfected with the WT-AR and treated with $0.1 \mathrm{nM}\left[\mathrm{H}^{3}\right]-\mathrm{R} 1881$ and a competitor ligand at the indicated doses for 2 hours. Lysates were subjected to scintillation counting and normalized to total protein amounts. Values in parentheses indicate the $\mathrm{IC}_{50}$ of each compound. Error bars represent the SD of duplicate samples from a representative experiment performed in triplicate. (C) CV1 cells were transfected with the WT-AR, MMTV-Luc, and Renilla-Luc and then treated with $0.1 \mathrm{nM}$ R1881 and the indicated dose of antagonist for 24 hours. Dual-luciferase values were measured and normalized to Renilla-Luc. Error bars indicate the SD of triplicate samples of a representative experiment performed in triplicate. Quantitative PCR (qPCR) analysis was performed, and heatmaps were generated for AR target gene activation of LNCaP cells treated with (D) vehicle DMSO (Veh) or (E) $10 \mathrm{nM}$ testosterone and $10 \mu \mathrm{M}$ of the indicated ligand for 24 hours. (F) In-cell Western analysis using an AR antibody was performed on LNCaP cells treated with increasing concentrations of the indicated ligand for 24 hours. Geldanamycin (Geld), an HSP9O inhibitor, was included as a positive control for AR degradation. AR protein expression was assessed using the LI-COR Odyssey imaging system, normalizing to DRAQ5 (DNA dye). Error bars represent the SD of triplicate wells of a representative experiment performed in triplicate. (C) Western blot analysis was performed on LNCaP cells treated with vehicle DMSO, 1.0 nM testosterone (T), $1.0 \mu M$ geldanamycin, or $10 \mu \mathrm{M}$ of antagonist for 24 hours. Blots were probed for the AR or $\beta$-actin as a loading control. Abi, abiraterone; Bic, bicalutamide; Enz, enzalutamide; Gal, galeterone; Ket, ketoconazole; OHF, hydroxyflutamide; Ort, orteronel; Sevi, seviteronel.

tidase 3 (KLK3) and NK3 homeobox 1 (NKX3.1) genes are presented in Supplemental Figure 3.

To evaluate whether alterations in AR protein levels could be responsible for the AR target gene expression changes observed in LNCaP cells, we performed in-cell Western analysis with increasing doses of CYP17 inhibitor treatment. Changes in AR protein levels were not detected with CYP17 inhibitor treatment, even at concentrations of up to $20 \mu \mathrm{M}$, despite a dose-dependent decrease with geldanamycin, an HSP90 inhibitor (Figure 1F) (40). We confirmed these results with conventional Western blot analysis (Figure 1G; see complete unedited blots in the supplemental material). Previous reports have demonstrated degradation of the $\mathrm{AR}$ with galeterone and, in some cases, abiraterone treatment in LNCaP cells (30-33). However, the results presented here suggest that degradation of the AR does not explain the AR antagonism demonstrated by CYP17 inhibitors. Collectively, these results suggest that, in addition to decreasing the synthesis of androgen precursors, the direct AR antagonism exhibited by seviteronel, galeterone, and abiraterone is likely to be important for the clinical efficacy of these inhibitors.

Inhibition of prostate cancer cell growth by CYP17 inhibitors. Having established direct AR antagonism of endogenous target genes in LNCaP cells by CYP17 inhibitors, we tested whether the antagonist activity of these compounds was sufficient to inhibit androgenresponsive growth of prostate cancer cells. As shown in Figure 2A, seviteronel, galeterone, and abiraterone antagonized the prolifer-
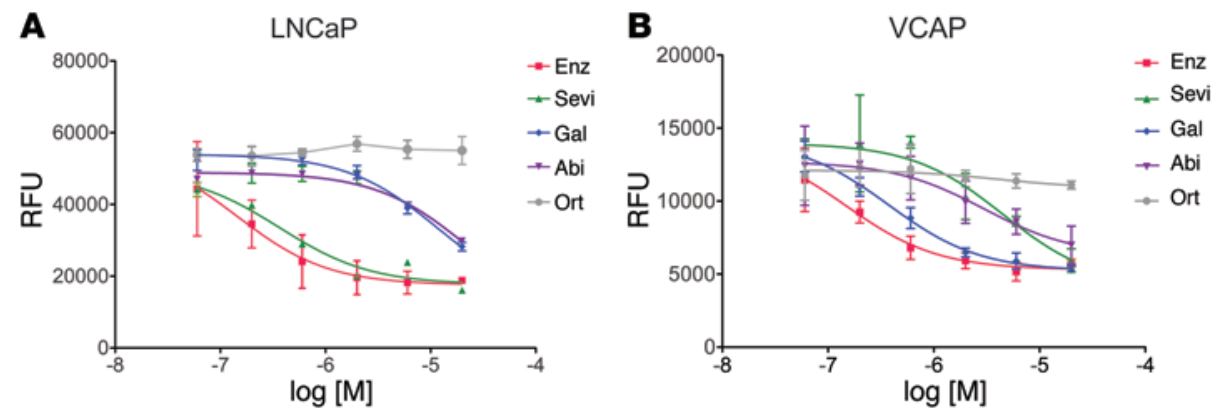

Figure 2. CYP17 inhibitors block androgen-mediated growth of AR-expressing prostate cancer cells. (A) LNCaP and (B) VCAP cells were treated with 1.0 and $0.1 \mathrm{nM}$ testosterone, respectively, and increasing doses of indicated antagonist. Following a 7-day incubation, proliferation was measured by assessing DNA content using Hoechst dye. Error bars represent the SD of triplicate samples of a representative experiment performed in triplicate. RFU, relative fluorescence units. ative response of $\mathrm{LNCaP}$ cells to androgens in a dose-responsive manner. Since LNCaP cells express the AR-T877A point mutation associated with flutamide and abiraterone resistance, we also confirmed the inhibitory activity of these compounds on androgenmediated growth of VCAP cells, which express the WT-AR (Figure 2B). Interestingly, seviteronel was more potent in LNCaP cells than in VCAP cells $\left(\mathrm{IC}_{50}\right.$ values of $3.67 \times 10^{-7}$ and $4.56 \times 10^{-6}$, respectively), suggesting that it may interact with the AR-T877A receptor variant with higher affinity than with the WT-AR. Cell-cycle analysis demonstrated that CYP17 inhibitors blocked androgen-mediated progression of LNCaP cells from the $G_{1}$ to $S$ phase (Supplemental Figure 4). CYP17 inhibitor treatment had minimal effects on the growth of AR-negative DU145 prostate cancer cells (Supplemental Figure 5). Further, it should be noted that, at concentrations above $10 \mu \mathrm{M}$, all 3 CYP17 inhibitors showed some off-target toxicity (morphological hallmarks of apoptosis, e.g., blebbing) in the 7-day proliferation assay, which was not apparent at more clinically relevant lower doses or when assayed for shorter treatment periods. In agreement with the results of the binding and transcriptional assays, we found that orteronel was unable to antagonize androgen-mediated growth of either LNCaP or VCAP cells.

The conformation adopted by the AR upon binding CYP17 inhibitors mirrors that of the apo receptor. Previously, we reported on the development and validation of a cell-based AR conformationprofiling tool that utilizes peptide probes derived from nuclear receptor coregulators to survey ligand-induced alterations on the surface of the receptor $(41,42)$. This tool leverages the observation that receptor conformation, a primary determinant of coregulator recruitment, is predictive of the pharmacological activity of AR ligands. For this study, we developed a variation of the original tool (different coregulator-derived peptides) that enabled a useful discrimination of AR antagonist conformations. This was used to compare the impact of CYP17 inhibitors on AR conformation with those conformations induced by benchmark antagonists (Figure 3A). The results of this analysis indicate that the AR antagonists utilized in this study can be grouped into 4 distinct clusters: 
A

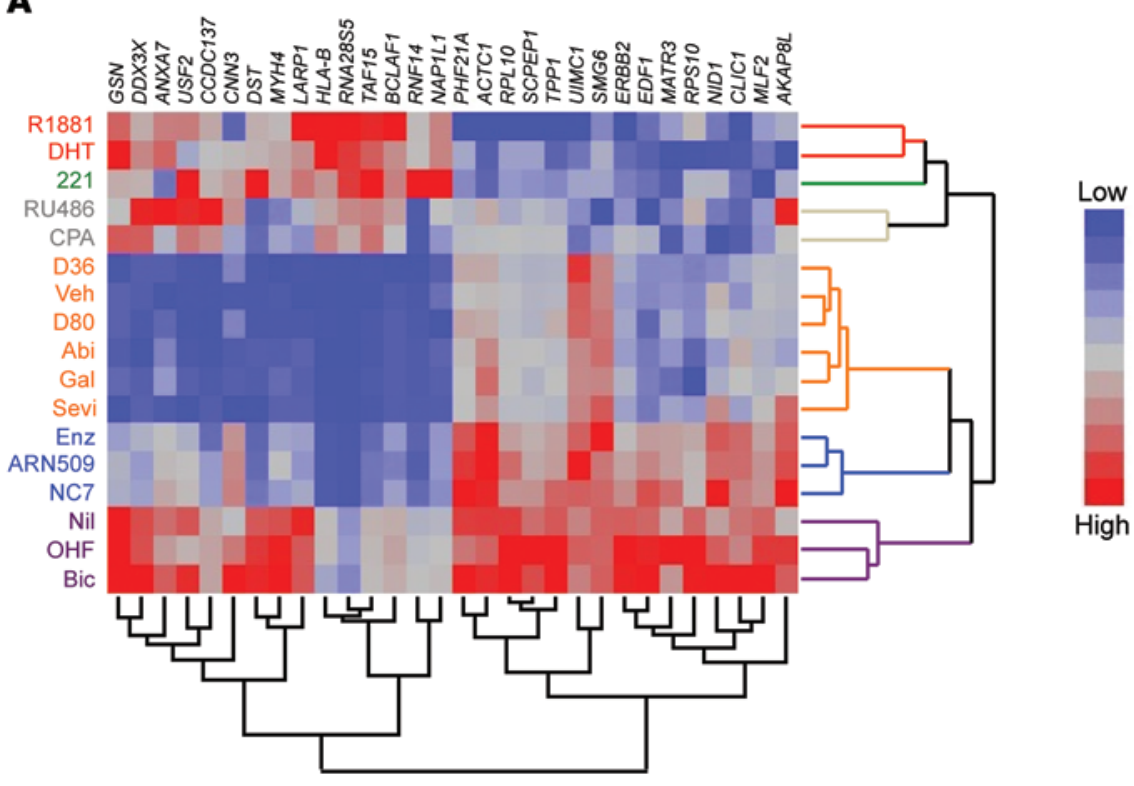

B
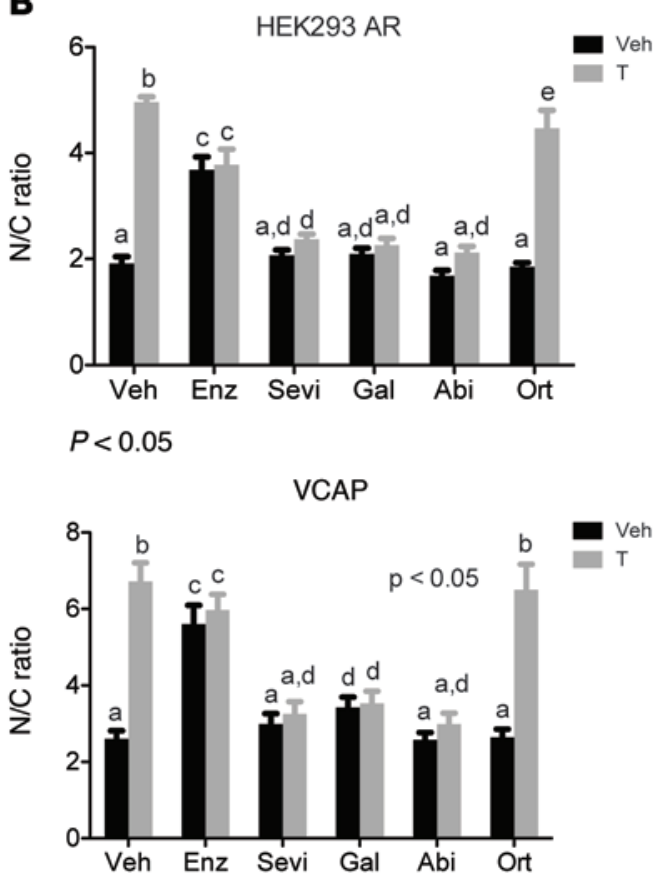

C
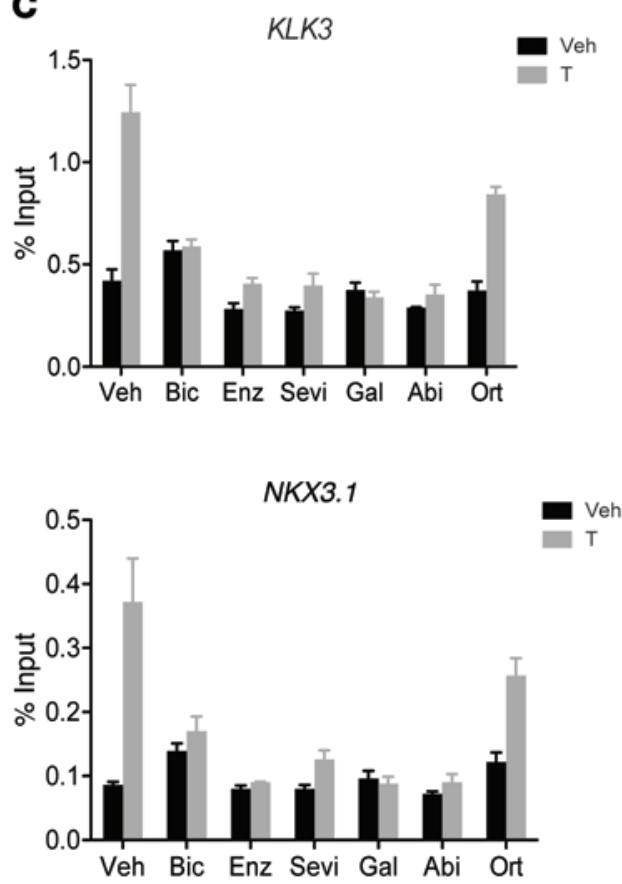

Figure 3. CYP17 inhibitors are mechanistically distinct antiandrogens. (A) CYP17 inhibitors induced novel AR conformation. Mammalian 2-hybrid-based AR coregulator-profiling assays were performed using HepG2 cells trans fected with VP16-AR, 5XGalLuc3, Gal4-coregulator interactor, and Renilla-Luc. Cells were induced with the indicated ligand, and dual-luciferase assays were performed. Data were standardized to avoid bias due to signal strength and clustered with the Ward hierarchical clustering method using JMP. DHT, dihydrotestosterone; CPA, cyproterone acetate; Nil, nilutamide. (B) CYP17 inhibitors blocked androgen-mediated AR nuclear accumulation. HEK293 (transfected with the WT-AR) and VCAP cells were treated with vehicle or $0.3 \mathrm{nM}$ testosterone plus $10 \mu \mathrm{M}$ of the indicated antagonist for 4 hours. Cells were stained for the AR, DAPI, and phalloidin, and nuclear/cytoplasmic ( $\mathrm{N} / \mathrm{C}$ ) ratios were quantified using highcontent imaging (ArrayScan). Error bars represent the SEM from 7 to 9 independent experiments. Letters indicate statistically similar groups $(P<0.05)$ as determined by 1-way ANOVA analysis followed by Bonferroni's multiple comparisons test. (C) CYP17 inhibitors blocked association of the AR with DNA. LNCaP cells were treated with the indicated ligand $(10 \mu \mathrm{M})$ for 4 hours in the presence of vehicle or $1.0 \mathrm{nM}$ testosterone, and ChIP assays were performed with an AR antibody. $A R$ enhancer occupancy was determined by qPCR analysis and calculated as the percentage of input. Error bars indicate the SD of triplicate qPCR samples from a representative experiment performed in triplicate. (a) AR antagonists, flutamide (43), bicalutamide (4), and nilutamide (44), which function as partial agonists in models of CRPC (purple cluster); (b) RU486 (45) and cyproterone acetate (CPA) (46) (gray cluster); (c) enzalutamide and its structurally related analogs ARN509 and NC7 (11); and (d) seviteronel, galeterone, and abiraterone (orange cluster). Additional ligands found to cluster with the CYP17 inhibitors include D36 and D80, two noncompetitive AR antagonists that we previously reported to have efficacy in models of CRPC (47). The red and green clusters represent the conformations induced by full agonists (R1881 and DHT) and the selective AR modulator (SARM) 221 (S4), respectively (48). Interestingly, the conformational change in the AR induced by the CYP17 inhibitors most closely resembles the unliganded AR (apo-AR), suggesting that these compounds are mechanistically distinct from other classes of AR antagonists and may, therefore, have clinical utility in contexts in which existing antagonists have proven ineffective.

Nuclear accumulation and DNA binding of the AR are attenuated by CYP17 inhibitors. In the absence of hormone, the AR is associated with a HSP complex that sequesters the receptor in the cytoplasm and maintains it in a transcriptionally inactive state. Agonist binding disrupts the inhibitory HSP-AR complex, exposing a nuclear localization signal in the receptor that enables nuclear translocation (49). We used high-content imaging (Cellomics ArrayScan) to evaluate the subcellular localization of the AR in an unbiased manner in AR-transfected HEK293 and VCAP cells 
A
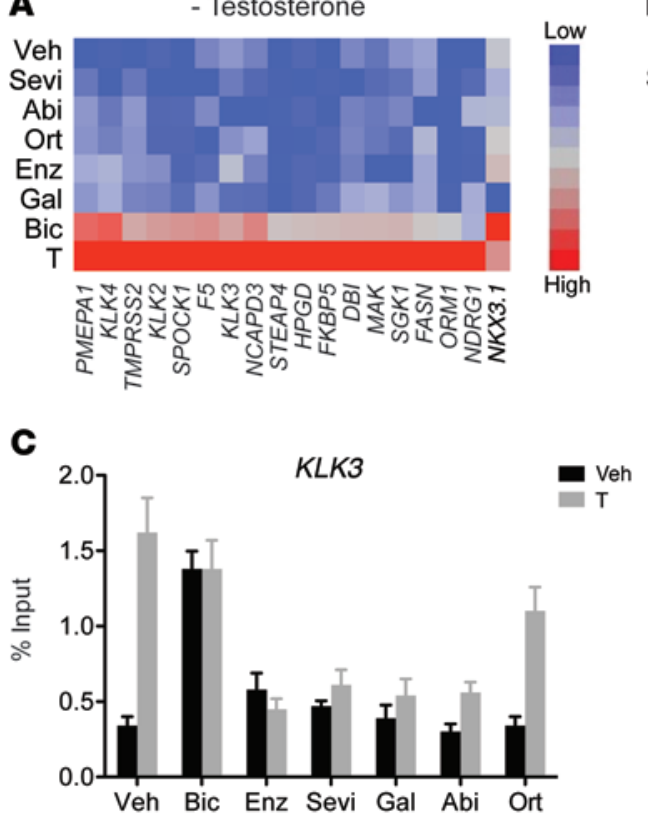

B

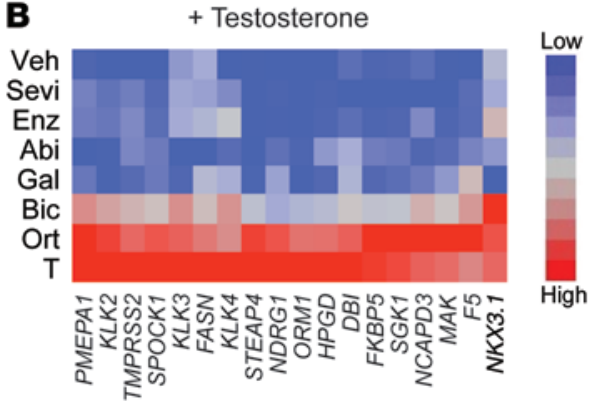

D

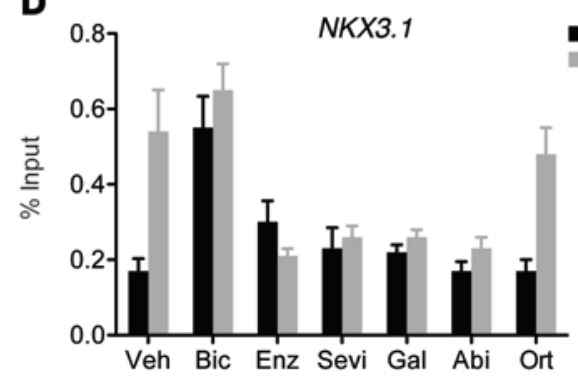

Figure 4. Activity of CYP17 inhibitors in AR-overexpressing CRPC. (A) LNCaP cells stably overexpress ing the AR ( $L N C a P-A R)$ were treated for 24 hours with vehicle or (B) $1.0 \mathrm{nM}$ testosterone plus $10 \mu \mathrm{M}$ of the indicated ligand. qPCR analysis was performed on a validated set of AR-regulated genes and presented as heatmaps. (C) ChIP assays were performed using an AR antibody in LNCaP-AR cells treated with the indicated ligands for 4 hours (vehicle or $1.0 \mathrm{nM}$ testosterone plus $10 \mu \mathrm{M}$ antagonist). AR enhancer occupancy was determined by qPCR and calculated as a percentage of input. Error bars indicate the SD of triplicate qPCR samples from a representative experiment performed in triplicate. following treatment with CYP17 inhibitors. As expected, the treatment of cells with testosterone resulted in robust nuclear accumulation of the AR (Figure 3B). Under these experimental conditions, enzalutamide treatment also facilitated nuclear translocation of the AR, albeit to a lesser extent than did testosterone, and, further, this antagonist did not prevent testosterone-mediated accumulation of the receptor in the nucleus. In contrast, none of the 3 CYP17 inhibitors studied promoted AR nuclear translocation, and, importantly, each attenuated testosterone-mediated nuclear accumulation of the receptor, with the exception of orteronel.

The ability of CYP17 inhibitors to regulate AR-DNA interactions was further assessed using ChIP assays in LNCaP cells. We found in these studies that treatment with a CYP17 inhibitor alone did not enable AR binding at the KLK3 or NKX3.1 genes, and, importantly, the CYP17 inhibitors prevented androgen-induced AR recruitment (Figure 3C). In agreement with previous assays, we found that orteronel was without effect. Although we observed nuclear accumulation of the AR in enzalutamide-treated cells (above), this did not result in the interaction of the receptor with DNA, and, not unexpectedly, this drug effectively blocked testosterone-dependent interaction of the AR with DNA. It appears, therefore, that the CYP17 inhibitors studied here function as mechanistically distinct $\mathrm{AR}$ antagonists, inducing a unique conformation in the receptor that mimics the apo receptor, preventing AR translocation to the nucleus and attenuating its interaction with target gene enhancers.

CYP17 inhibitors function as antagonists in AR-overexpressing CRPC. AR overexpression has emerged as one of the dominant mechanisms underlying resistance to androgen-ablative therapies in prostate cancer (50). Indeed, the ability of enzalutamide to inhibit AR signaling in the context of increased receptor expression was a key factor in its development and distinguishes it from earlier-generation AR antagonists (11). Thus, CYP17 inhibitors were evaluated for their ability to directly antagonize AR activity in LNCaP cells engineered to overexpress the AR (LNCaP-AR). As expected, gene expression analysis revealed that bicalutamide, but not enzalutamide, functioned as a partial agonist in this model (Figure 4A). Importantly, seviteronel, galeterone, and abiraterone also failed to demonstrate any intrinsic agonist activity when the AR was overexpressed. When tested for their ability to inhibit androgen-mediated target gene expression in LNCaP-AR cells, the CYP17 inhibitors were as effective as enzalutamide (Figure $4 \mathrm{~B})$. In addition to heatmaps, individual graphs showing $K L K 3$ and NKX3.1 gene expression are presented in Supplemental Figure 6.

To further characterize the mechanisms by which the CYP17 inhibitors manifest antagonist activity in CRPC, we assessed their ability to modulate AR-DNA interactions in the LNCaP-AR model (Figure 4C). These studies revealed that the bicalutamide-AR complex interacted with the androgen response elements (AREs) within the KLK3 and NKX3.1 genes. In contrast, neither enzalutamide nor CYP17 inhibitor treatment enabled interaction of the AR with DNA, and these compounds, absent orteronel, effectively inhibited androgen-induced AR recruitment to relevant enhancers. These results indicate that, in addition to suppression of adrenal/ intratumoral androgen production, the efficacy of abiraterone in metastatic CRPC may also relate to its ability to directly antagonize the AR, even when its expression is elevated. It is likely that seviteronel and galeterone function similarly in this setting.

CYP17 inhibitors antagonize the transcriptional activity of $A R$ mutants expressed in CRPC. In addition to enhanced AR expression, there is considerable evidence to suggest that mutations in the AR that alter its response to pharmacological agents may also be important in $\operatorname{CRPC}(6,21,23)$. Specifically, treatment failure in patients progressing while on antiandrogens has been attributed to point mutations in the AR: flutamide, T877A; bicalutamide, W741C; and enzalutamide, F876L (6, 21, 24-27). There is also recent evidence that the T877A mutation may be causally involved in resistance to abiraterone $(21,28,29)$. To gain a better understanding of the therapeutic potential of CYP17 inhibitors in antiandrogen-resistant CRPC, we assessed the ability of CYP17 inhibitors and benchmark AR antagonists to inhibit mutant AR 


\section{Table 1. CYP17 inhibitors antagonize mutant AR transcriptional activity}

$\begin{array}{lccc} & \text { T877A } & \text { W741C } & \text { F876L } \\ \text { Enzalutamide } & 3.04 \pm 1.17 \times 10^{-7} & 1.44 \pm 0.28 \times 10^{-6} & \text { Agonist } \\ \text { Bicalutamide } & 3.38 \pm 0.10 \times 10^{-7} & \text { Agonist } & 2.73 \pm 0.12 \times 10^{-7} \\ \text { Hydroxyflutamide } & \text { Agonist } & 1.96 \pm 0.40 \times 10^{-8} & 4.15 \pm 1.36 \times 10^{-8} \\ \text { Seviteronel } & 3.84 \pm 0.37 \times 10^{-7} & 2.13 \pm 0.15 \times 10^{-5} & 1.29 \pm 0.13 \times 10^{-6} \\ \text { Galeterone } & 3.35 \pm 0.95 \times 10^{-6} & 3.79 \pm 0.33 \times 10^{-7} & 9.88 \pm 1.55 \times 10^{-8} \\ \text { Abiraterone } & 2.43 \pm 0.53 \times 10^{-6} & 2.23 \pm 1.20 \times 10^{-6} & 4.06 \pm 0.04 \times 10^{-7} \\ \text { Orteronel } & >100 \mu \mathrm{M} & >100 \mu \mathrm{M} & >100 \mu \mathrm{M}\end{array}$

Transcriptional IC $C_{50}$ values ( \pm SEM of 3 independent experiments) were determined by adding increasing concentrations of the test ligand in the presence of the synthetic AR agonist R1881 (0.1 nM for WT-AR, T877A, and W741C; 0.3 nM for F876L).

transcriptional activity in a cell-based reporter gene assay (Table 1). On the AR-T877A mutation, hydroxyflutamide activated, while enzalutamide and bicalutamide inhibited, transcription. Importantly, seviteronel, galeterone, and abiraterone all antagonized AR-T877A activity, with seviteronel being the most potent. This latter property likely explains the more robust antiproliferative activity of seviteronel observed in the LNCaP (AR-T877A) versus VCAP (WT-AR) model systems (Figure 2). The AR-W741C mutation enabled an antagonist-to-agonist switch with bicalutamide but was effectively antagonized by the other antiandrogens tested and with seviteronel, galeterone, and abiraterone. The AR-F876L mutation appears to be associated with enzalutamide resistance, and we have confirmed that this mutation enables this antiandrogen to manifest agonist activity $(21,24,25)$. This mutation did not affect the antagonist activity of hydroxyflutamide or bicalutamide, and, further, its activity was inhibited by seviteronel, galeterone, and abiraterone. None of the CYP17 inhibitors studied exhibited intrinsic agonist activity on any receptor mutation tested (Supplemental Figure 7). It is also of note that, similar to observations in studies with the WT-AR, orteronel failed to inhibit the transcriptional activity of antiandrogen-resistant AR variants, even at concentrations of up to $100 \mu \mathrm{M}$ (Table 1 ).

Activity of CYP17 inhibitors in AR-F876L enzalutamide-resistant $C R P C$. Encouraged by the results of the reporter gene studies noted above, we evaluated CYP17 inhibitors for their ability to regulate endogenous AR target gene transcription in $\mathrm{LNCaP}$ cells engineered to overexpress AR-F876L. In this assay, enzalutamide was as effective as testosterone at activating AR target gene transcription, whereas seviteronel, galeterone, and abiraterone were without effect (Figure 5A). Importantly, all 3 CYP17 inhibitors were able to antagonize testosterone activity in these cells (Figure 5B). In addition to the heatmaps, individual graphs showing $K L K 3$ and NKX3.1 gene expression are presented in Supplemental Figure 8.

We next assessed the impact of CYP17 inhibitors on the subcellular localization of AR-F876L and its DNA-binding activities. As we observed for the WT-AR, the addition of testosterone or enzalutamide resulted in robust nuclear accumulation of AR-F876L (Figure 5C). The addition of seviteronel, galeterone, or abiraterone did not stimulate significant AR-F876L nuclear accumulation compared with that seen with the vehicle, and these agents reduced the testosterone-mediated nuclear translocation of the AR. Enzalutamide has been shown to promote the binding of AR-F876L to the regulatory regions of target genes, thus accounting for its ability to induce AR target gene transcription in cells expressing this mutant (24). Consistent with the data from immunocytochemistry studies, ChIP analysis revealed that treatment with enzalutamide, but not the CYP17 inhibitors, enabled the interaction of LNCaP-F876L with AREs in the KLK3 and NKX3.1 genes (Figure 5D). Indeed, CYP17 inhibitors interfered with testosterone-induced recruitment of AR-F876L to these enhancers. Collectively, these results indicate that CYP17 inhibitors may have therapeutic utility in the management of CRPC patients who fail enzalutamide therapy secondary to the selection for the AR-F876L mutation.

To further explore the potential of CYP17 inhibitors in CRPC, we assessed the effects of seviteronel, galeterone, and abiraterone on the growth of AR-overexpressing (LNCaP-AR) or enzalutamideresistant (LNCaP-F876L) prostate cancer cells. Consistent with the findings of the gene expression studies, we found that bicalutamide and enzalutamide treatment increased the proliferation of LNCaPAR and LNCaP-F876L cells, respectively; however, CYP17 inhibitors were without effect in either cell line (Figure 6, A and B). Androgens promoted the growth of both LNCaP-AR and LNCaP-F876L cells in a dose-dependent manner (Supplemental Figure 9). These results highlight the important mechanistic differences exhibited by CYP17 inhibitors when compared with the first- and secondgeneration AR antagonists bicalutamide and enzalutamide.

Growth of both hormone-sensitive and enzalutamide-resistant CRPC tumors is inhibited by CYP17 inhibitors. Given the observation that CYP17 inhibitors interact with and inhibit the transcriptional activity of both the WT-AR and AR mutants, combined with the observations that PSA and testosterone levels were uncoupled in a CRPC patient on seviteronel (37), we considered it likely that this activity contributed to the antitumor efficacy of this class of drugs. Xenograft studies were first initiated using LNCaP cells to assess the effects of CYP17 inhibitors on hormone-sensitive tumor growth and to establish the effective dose of seviteronel before comparison with other compounds. LNCaP tumors were initiated in 6-week-old immunodeficient, intact male SCID mice, and when tumors reached a volume of approximately $0.15 \mathrm{~cm}^{3}$, the mice were randomized to daily treatment with vehicle or seviteronel $(15,50$, or $100 \mathrm{mg} / \mathrm{kg}$ bid). Over a 28 -day period of treatment, only the $100-\mathrm{mg} / \mathrm{kg}$ dose significantly inhibited tumor growth (Supplemental Figure 10A). To confirm the AR antagonist activity of seviteronel in vivo, we performed a pharmacodynamic study in LNCaP tumor-bearing mice supplemented with exogenous testosterone. As shown in Supplemental Figure 10B, seviteronel treatment resulted in significant inhibition of tumor-derived AR target genes, even when testosterone was present.

Having established an effective dose of seviteronel, we evaluated the activities of seviteronel and abiraterone on the growth of enzalutamide-resistant LNCaP-F876L xenografts in studies designed to isolate the CYP17-inhibitory activity from the AR antagonist activity. For this study, mice were castrated prior to tumor initiation, and testosterone treatment pellets $(12.5 \mathrm{mg} / 90$ day pellet) were simultaneously implanted into mice in $1 \mathrm{arm}$ $(+\mathrm{T})$ of the study. When tumors reached approximately $0.15 \mathrm{~cm}^{3}$ in size, mice in both the castration and castration $+\mathrm{T}$ arms of the 
A

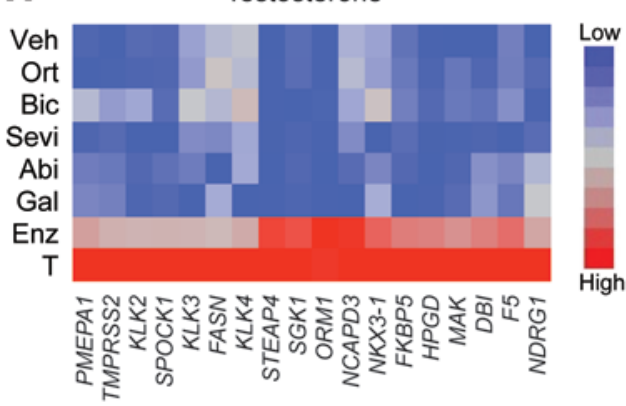

B
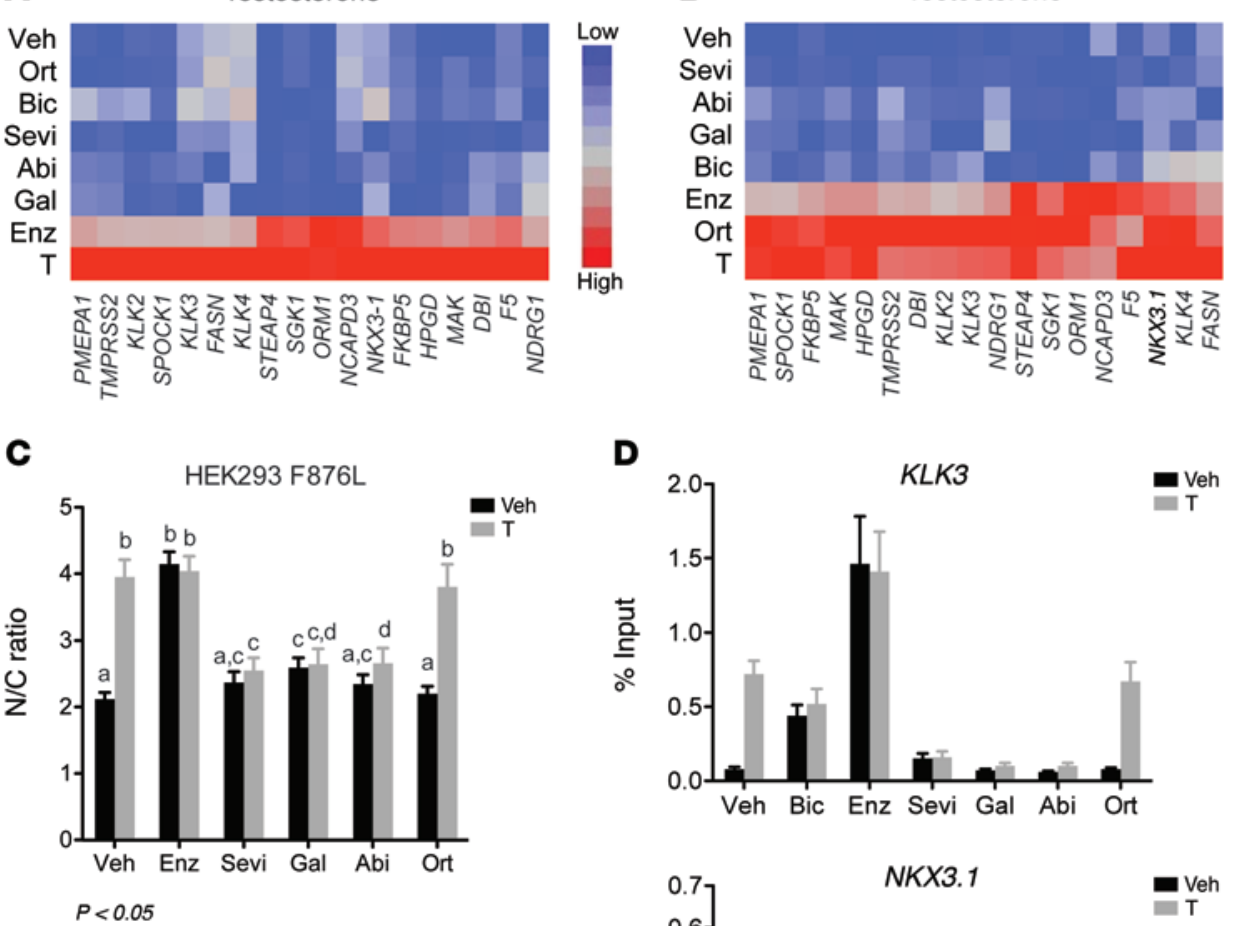

D
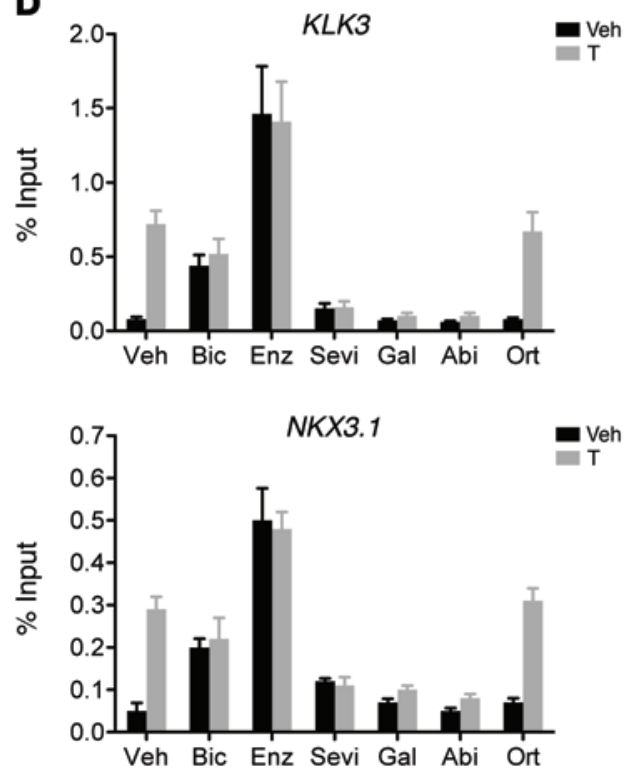

Figure 5. Activity of CYP17 inhibitors in AR-F876L-expressing cells. (A)

LNCaP cells engineered to stably express the AR-F876L enzalutamideresistant $A R$ mutation were treated with vehicle or (B) $3.0 \mathrm{nM}$ testosterone plus $10 \mu \mathrm{M}$ of the indicated antagonist for 24 hours. AR target genes were assessed by qPCR, and data are presented as heatmaps. (C) HEK293 cells were transfected with an AR-F876L expression plasmid and treated with the indicated ligands ( $10 \mu \mathrm{M}$ antagonist plus vehicle or $0.3 \mathrm{nM}$ testosterone) for 4 hours. High-content imaging was performed on fixed cells that were stained for the AR, phalloidin, and DAPI, and the $A R N / C$ ratio is reported. Error bars represent the SEM from 7 to 9 independent experiments. Letters indicate statistically similar groups $(P<0.05)$ as determined by 1 -way ANOVA analysis followed by Bonferroni's multiple comparisons test. (D) ChIP analysis was performed in LNCaP-F876L cells treated with vehicle or $1.0 \mathrm{nM}$ testosterone and $10 \mu \mathrm{M}$ of the indicated antagonist for 4 hours. Error bars represent the SD of triplicate qPCR samples from a representative experiment performed in triplicate. study were randomized to treatment with vehicle, enzalutamide (30 mg/kg qd), seviteronel, or abiraterone (both $100 \mathrm{mg} / \mathrm{kg}$ bid). As expected, enzalutamide had no effect on LNCaP-F876L tumor growth under either condition (Figure 7, A and B). The growth of these tumors was also unaffected by testosterone administration, despite a 5 -fold difference in seminal vesicle weight, indicating androgen exposure (Supplemental Figure 11A). During the 28 days of treatment, both seviteronel and abiraterone significantly inhibited tumor growth $(P<0.0001)$, regardless of testosterone administration (Figure 7, A and B). The asterisks denote the time points at which the average tumor volume in the animals treated with seviteronel differed significantly from that observed in animals treated with abiraterone. Analysis of plasma retained after euthanasia indicated that the drug exposure was similar to that observed in patients (Supplemental Figure 11B) (51-53). These results demonstrate that enzalutamide-resistant tumors expressing the AR-F876L mutation can be inhibited by treatment with seviteronel or abiraterone. Furthermore, seviteronel and abiraterone significantly inhibited tumor growth in the presence of exogenous testosterone, supporting the role of AR antagonism in their mechanisms of action.

\section{Discussion}

Although developed for their ability to inhibit the production of androgens, it has recently been suggested that CYP17 inhibitors, or their metabolites, may also function directly as AR antagonists (16,
A

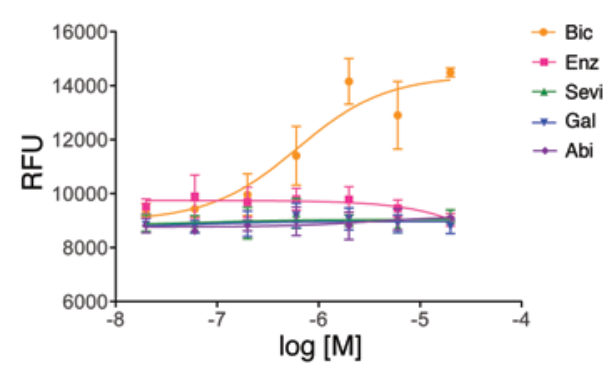

B

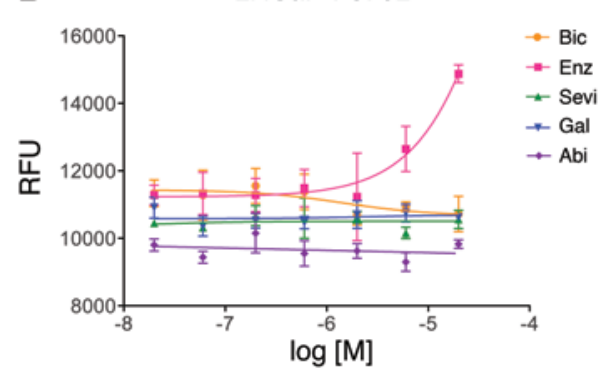

Figure 6. CYP17 inhibitors do not promote the proliferation of AR overexpression or enzalutamide-resistant CRPC models. Proliferation assays were performed in (A) LNCaP-AR and (B) LNCaP-F876L cells after 7 days of growth in the presence of the indicated ligand. Error bars indicate the SD of triplicate samples from a representative experiment performed in triplicate. 
A

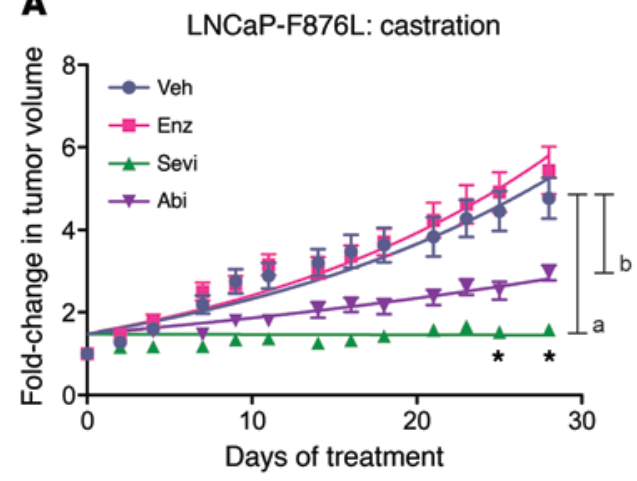

B

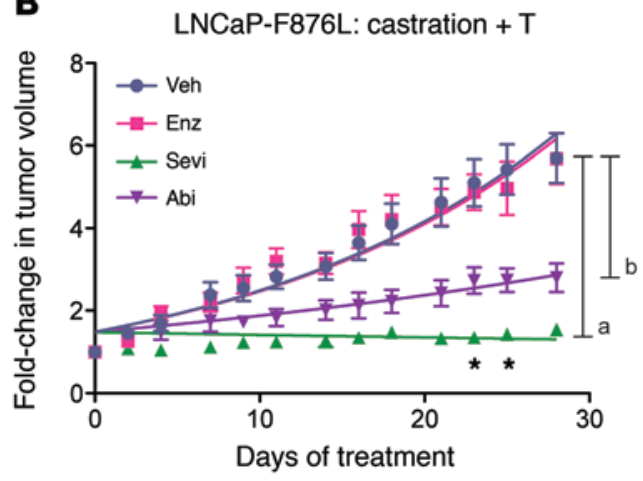

Figure 7. Inhibition of enzalutamide-resistant CRPC tumor growth by CYP17 inhibitors. (A) LNCaP-F876L cells were implanted into the flanks of castrated male SCID mice. Following tumor development $(\sim 0.15 \mathrm{~cm} 3)$, mice $(n=13)$ were randomized to treatment with vehicle, enzalutamide ( $30 \mathrm{mg} / \mathrm{kg} \mathrm{qd})$, seviteronel $(100 \mathrm{mg} / \mathrm{kg}$ bid), or abiraterone $(100 \mathrm{mg} / \mathrm{kg}$ bid), and tumor volumes were followed for 28 days. Seviteronel and abiraterone both significantly inhibited growth compared with vehicle $(P<0.0001)(\mathbf{A}$ and $\mathbf{B})$. Asterisks $\left(^{*}\right)$ indicate the points at which the average tumor volumes in the seviteronel-treated mice were statistically significant from those in the abiraterone-treated mice $(P<0.05)$. (B) Same as in A, except mice were implanted with testosterone pellets at the time of castration. $\mathbf{P}<0.0001$ (A and $\mathbf{B}$ ). Statistical significance for all comparisons was determined by 2-way ANOVA followed by Bonferroni multiple comparison test.

30-36). However, the extent to which AR antagonism influences the clinical efficacy of CYP17 inhibitors has not been elucidated. In this study, it was demonstrated that CYP17 inhibitors (abiraterone, seviteronel, and galeterone) directly antagonized AR signaling in multiple validated models of CRPC. This group of CYP17 inhibitors was as effective as enzalutamide in preventing the interaction of the AR with DNA and inhibiting AR target gene transcription in cells engineered to overexpress the receptor. These drugs also demonstrated efficacy against those AR mutations (enzalutamide, F876L; flutamide, T877A; bicalutamide, W741C) that are associated with resistance to endocrine therapy $(6,21,24-27)$. Importantly, the ability of seviteronel and abiraterone to inhibit the growth of enzalutamide-resistant xenografts through direct antagonism of AR-F876L activity provides compelling evidence that the antiandrogenic activity of CYP17 inhibitors is manifest in vivo. Furthermore, the observed decrease in PSA absent a decline in testosterone levels in a seviteronel-treated patient suggests that AR antagonism can impact the clinical efficacy of CYP17 inhibitors (37).

Results from conformational profiling and AR subcellular distribution studies suggest that CYP17 inhibitors are mechanistically distinct from traditional antiandrogens. Together, our findings strengthen previous reports that have suggested AR antagonist properties of CYP17 inhibitors and expand upon their observed mechanism of action by showing that the conformation of the CYP17 inhibitor-bound AR is similar to the apo receptor and distinct from the conformations induced by firstand second-generation antiandrogens. Not surprisingly, given its structural similarity to the apo-AR, the AR-CYP17 inhibitor complex remains primarily localized in the cytoplasm, resulting in a lack of DNA binding and inhibition of cell growth in models of hormone-dependent and -independent prostate cancer. Past studies have reported on the ability of CYP17 inhibitors to directly antagonize the transcriptional activities of WT and mutant forms of the AR $(16,31-33)$. Galeterone has also been reported to induce degradation of the AR and the truncated AR variant $A R-V 7$, which is highly predictive of resistance to abiraterone and enzalutamide in CRPC (19, 30). Although previous studies have proposed that the mechanism of action of CYP17 inhibitors, galeterone in particular, involves degradation of the receptor, we did not detect any changes in AR protein levels with CYP17 inhibitor treatment, even at concentrations of up to $20 \mu \mathrm{M}$, despite a dose-dependent decrease in AR expression with geldanamycin, an HSP90 inhibitor (30-33). These findings are complicated further by reports demonstrating that the ability of galeterone to degrade the AR is specific to the AR-T877A mutation (33). Although these prior studies present equivocal findings with respect to the ability of galeterone to degrade the AR, we believe that our current study conclusively shows that AR degradation is not requisite for AR antagonism by CYP17 inhibitors.

Support for the development of CYP17 inhibitors began with studies using the antifungal ketoconazole off-label in prostate cancer therapy, resulting in decreases in circulating levels of testosterone (54). However, the clinical results with ketoconazole in CRPC were modest, and treatment with ketoconazole led to significant toxicities due to inhibition of multiple CYP enzymes $(38,39)$. More recently, discovery campaigns have focused on the development of specific CYP17 inhibitors to reduce androgen biosynthesis. The first drug of this class to be approved, abiraterone, was shown to significantly impact disease progression in patients with CRPC in 2 phase III clinical trials (COU-AA-301 and COU-AA-302) $(3,9)$. Importantly, appropriate drug exposure for abiraterone to directly impact WT or mutant AR activity is attainable in patients. In our studies, we demonstrated that the $\mathrm{IC}_{50}$ values for this compound in the WT-AR competitive binding and transcriptional assays were 7.6 and $9.4 \mu \mathrm{M}$, respectively. Furthermore, as evidenced by tumor inhibition of AR-F876L-expressing xenografts, abiraterone demonstrated substantial efficacy on the AR-F876L mutation, with an $\mathrm{IC}_{50}$ value of $0.41 \mu \mathrm{M}$. On the basis of the current recommended dosing regimen for abiraterone $(1,000 \mathrm{mg} /$ day $), \mathrm{a}_{\max }$ of approximately $0.65 \mu \mathrm{M}$ is achieved when taken without food (53). Abiraterone exposure can also be enhanced by up to 17 -fold when taken with a high-fat meal, and at these levels, the drug would be expected to occupy the WT-AR and the commonly occurring AR mutants (53). Furthermore, it is important to remember that, since abiraterone and other CYP17 inhibitors are extremely effective at lowering serum testosterone levels (undetectable levels of $<1 \mathrm{ng} /$ $\mathrm{dl}$ after 8 days of abiraterone treatment), it is unlikely that the AR in tumors will be exposed to androgens as in our in vitro assays, thereby effectively lowering the $\mathrm{IC}_{50}$ in patients and providing a 
possible mechanistic advantage of CYP17 inhibitors compared with that of pure antiandrogens (15). Studies have suggested that there is considerable cross-resistance to abiraterone in patients progressing on enzalutamide treatment, although a few patients did show decreases in their PSA levels $(55,56)$. It will be informative in future studies to address whether these responders were due to abiraterone-inhibitory activity on AR mutants, such as F876L. As previously mentioned, a metabolite of abiraterone, D4A, was also recently discovered to possess enhanced affinity for the AR and directly inhibit AR activity. The relative contribution of D4A to the clinical activity of abiraterone remains to be determined, as D4A concentrations in patients were variable (34). To our knowledge, no active metabolites of seviteronel or galeterone have been reported.

Seviteronel and galeterone emerged from programs whose goals were to develop inhibitors that did not impact the hydroxylase activity of the enzyme, thus negating the need for cortisol replacement $(16,18)$. In agreement with preclinical data showing minimal effects on CYP17 hydroxylase function, the initial phase I and II studies of seviteronel for CRPC have been conducted without supplemental steroids, indicating that it is possible to block adrenal androgen production without negatively impacting glucocorticoid production (51). The reported $\mathrm{C}_{\max }$ for seviteronel is $13 \mu \mathrm{M}$, a concentration that our data indicate as being sufficient to inhibit both the WT and mutant AR in patients (51). Interestingly, the AR-T877A mutation was previously found to be enriched in patients treated with abiraterone $(21,28,29)$. Progesterone, which accumulates upon abiraterone treatment due to CYP17 hydroxylase inhibition, can activate the T877A mutation (29). Glucocorticoids and mineralocorticoid receptor antagonists, drugs requisitely administered with abiraterone, can also activate $\operatorname{AR}-T 877 A(29,35)$. For these reasons, seviteronel, which demonstrated the most potent activity against AR-T877A, may have superior efficacy in this setting of resistance, since it does not increase progestins or require corticoid supplementation (51). Seviteronel phase II studies are ongoing in men with CRPC following abiraterone therapy (ClinicalTrials.gov identifiers NCT02012920 and NCT02445976).

Compared with the other CYP17 inhibitors, galeterone was the most potent inhibitor of the WT-AR, with $\mathrm{IC}_{50}$ values for binding and transcriptional assays of 0.55 and $0.77 \mu \mathrm{M}$, respectively. Since the $\mathrm{C}_{\max }$ of galeterone is approximately $2.8 \mu \mathrm{M}$ in patients, AR antagonism of the WT and mutant AR can be reached in tumor cells (57). In contrast to the other CYP17 inhibitors tested, orteronel had no activity on the WT or mutant AR. In recent phase III studies of CRPC, ELM-PC 4 (chemotherapy-naive) and ELM-PC 5 (progression on docetaxel), orteronel did not meet the primary overall survival endpoints $(58,59)$. The authors speculate that this resulted from patient crossover in Europe and North America to abiraterone and enzalutamide, which had been recently approved and were widely available in these areas. Our data and data from others raise the possibility that the inability of orteronel to inhibit the AR may limit its clinical efficacy and has played a factor in its failure to affect the overall survival of patients with CRPC (36).

Even though treatment options for CRPC have been expanded in recent years, patients will eventually succumb to metastatic disease, supporting the need for new therapeutics for resistant disease (50). In this study, we provide evidence that, in addition to decreasing testosterone production, the AR antagonist activity of seviteronel, abiraterone, and galeterone is probably important for the therapeutic activity of these agents. Indeed, the lack of AR antagonist activity for orteronel, coupled with its inability to significantly impact the overall survival of patients with CRPC, suggests that intracrine androgen synthesis is not a primary mechanism of resistance to antiendocrine therapies. However, as the AR remains a driver in CRPC, these data support the need for further research into the use of CYP17 inhibitors in patients whose tumors harbor increased AR expression or AR mutations, especially as cases of F876L mutation arise in enzalutamide-treated patients.

\section{Methods}

Cell culture. LNCaP cells were maintained in RPMI supplemented with 8\% FBS. CV1, VCAP, HEK293, DU145, and HepG2 cells were maintained in DMEM (8\% FBS). All cell lines were obtained from American Type Culture Collection (ATCC). Stable LNCaP cell lines expressing the WT-AR (LNCaP-AR), the F876L mutation (LNCaP-F876L), or empty vector control (LNCaP-XIP) were generated using pQC-XIP retrovirus vector (Promega).

Reagents. The following reagents were used: enzalutamide, bicalutamide, and hydroxyflutamide (Cayman Chemical Company); ketoconazole and orteronel (Seleckchem); testosterone, R1881, and [ $\left.{ }^{3} \mathrm{H}\right]-\mathrm{R} 1881$ (PerkinElmer); and seviteronel, galeterone, and abiraterone acetate (supplied by Innocrin Pharmaceuticals).

Whole-cell competition assay. HEK293 cells were transfected with pcDNA-AR vector using FuGENE6 Reagent (Promega). Cells (100,000 cells) were then seeded in DMEM supplemented with $8 \%$ charcoal-stripped fetal calf serum (FCS) on 24-well plates coated with $0.2 \%$ gelatin (Sigma-Aldrich). Following overnight incubation, cells were treated with the appropriate competitor ligand in the presence of $0.1 \mathrm{nM}\left[{ }^{3} \mathrm{H}\right]-\mathrm{R} 1881$ for 2 hours. Cells were then lysed in $200 \mu \mathrm{l} \mathrm{lysis} \mathrm{buffer}$ (2\% SDS, $10 \%$ glycerol, and $10 \mathrm{mM}$ Tris-HCl, $\mathrm{pH}$ 6.8) and diluted with an additional $300 \mu \mathrm{l}$ of $10 \mathrm{mM}$ Tris- $\mathrm{HCl}(\mathrm{pH} 8.0)$. Each sample (300 $\mu \mathrm{l})$ was added to $3 \mathrm{ml}$ Cytoscint (MP Biomedicals) and analyzed by scintillation counting (Beckman LS 6000SC). Data were normalized to total protein for each sample and measured by the Pierce BCA Protein Assay Kit (Thermo Fisher Scientific) following the manufacturer's instructions.

$A R$ reporter gene assay. CV1 cells were seeded in 96-well plates and transfected using Lipofectin Reagent (Invitrogen, Thermo Fisher Scientific) as described in the manufacturer's instructions. The DNA mixture for each 96-well plate consisted of $100 \mathrm{ng}$ pcDNA-AR (WT, T877A, W741C, or F876L), 2,400 ng MMTV-Luc (or PSA-Luc), and $500 \mathrm{ng}$ Renilla-Luc. After overnight incubation, cells were treated with hormone for 24 hours. Cells were then lysed and quantified for luciferase activity using a dual-luciferase reagent.

RNA isolation and quantitative real-time PCR. LNCaP, LNCaP-AR, and LNCaP-F876L cells were seeded in RPMI containing 8\% FCS in 12 -well plates. Cells were treated with the appropriate ligand 48 hours later. Total RNA was then isolated with the Aurum Total RNA Mini Kit (Bio-Rad) and reverse transcribed using the iScript cDNA Synthesis Kit (Bio-Rad). AR target gene levels were assessed by real-time PCR, normalizing to the GAPDH housekeeping gene.

In-cell Western assay. LNCaP cells were plated in RPMI supplemented with $8 \%$ FCS in 96-well clear-bottomed black plates $(20,000$ cells/well). After a 48-hour incubation, cells were treated with hormone for 18 hours. Cells were fixed with formaldehyde (3.7\%), permeabilized using PBS (0.1\% TRITON X-100), and incubated overnight 
with anti-AR antibody (N-20, 1:2,000; Santa Cruz Biotechnology Inc.). Cells were washed with PBS (0.1\% Tween), and stained with a secondary antibody (Biotium CF770 goat anti-rabbit, 1:2,000). AR protein expression was assessed using the LI-COR Odyssey Imaging System. DRAQ5 (DNA stain, 1:10,000; Thermo Fisher Scientific) was used to normalize AR protein expression.

Western blot analysis. LNCaP cells were plated in 6-well plates in RPMI with $8 \%$ FCS. Two days later, cells were treated overnight with the indicated hormone. Cells were collected in PBS, pelleted, and lysed (50 mM Tris, pH 7.5, $150 \mathrm{mM} \mathrm{NaCl}, 1 \% \mathrm{NP}-40,0.5 \%$ sodium deoxycholate, $0.05 \%$ SDS, $5 \mathrm{mM}$ EDTA, $50 \mathrm{mM} \mathrm{NaF}, 15 \mathrm{mM}$ sodium pyrophosphate, $10 \mathrm{mM} \beta$-glycerophosphate, $2 \mathrm{mM}$ sodium orthovanadate, and $1 \times$ protease inhibitor cocktail). Cleared lysates were quantified using the Bradford Protein Assay (Bio-Rad) and analyzed by SDS-PAGE. Blots were probed for AR expression (N-20, 1:2,000; Santa Cruz Biotechnology Inc.), with $\beta$-actin used as a loading control (AC-15, 1:20,000; Sigma-Aldrich).

Cell proliferation assay. LNCaP, LNCaP-AR, LNCaP-F876L, VCAP, or DU145 cells (10,000/well) were plated in 96-well tissue culture plates and treated with hormone for 7 days. Cellular proliferation was assessed by measuring DNA content with Hoechst dye.

AR conformation-profiling assay. HepG2 cells were maintained in Basal Medium Eagle (Sigma Aldrich) containing 8\% FBS. For mammalian 2-hybrid-based AR cofactor assays $(41,42)$, cells were seeded in 96-well plates and transfected with VP16-AR (900 ng), 5XGalLuc3 (900 ng), Gal4-interactor (900 ng), and Renilla-Luc (300 ng) using Lipofectin (Thermo Fisher Scientific). Cells were then treated with the ligands as indicated in Figure legend 3 for 48 hours, at which point, dual-luciferase assays were performed. The data were standardized to avoid bias due to signal strength and clustered with the Ward hierarchical clustering method using JMP (SAS Institute Inc.). The hierarchical cluster dendrogram was ordered by the first principal component.

$A R$ protein localization. Cells were stained for the AR and analyzed by high-content imaging as described previously (42). Briefly, HEK293 or VCAP cells were fixed with $4 \%$ paraformaldehyde, permeabilized with Triton X-100 (0.1\%), stained for AR expression (1:400, N-20; Santa Cruz Biotechnology Inc.), and counterstained for DNA (DAPI; Sigma-Aldrich) and F-actin (rhodamine phalloidin; Thermo Fisher Scientific). The Cellomics ArrayScan VTI HCS system (Thermo Fisher Scientific) was used to image cells with the Compartmental Analysis Bioapplication. The nuclear/cytoplasmic ratio of AR staining is reported in Figure 5C.

ChIP. LNCaP, LNCaP-AR, or LNCaP-F876L cells were plated in RPMI containing $8 \%$ FCS in $150-\mathrm{mm}$ tissue culture plates. Two days later, cells were treated with the appropriate ligand for 4 hours, followed by fixation with $1 \%$ formaldehyde (added directly to the media) for 10 minutes at room temperature. Cross-linking was quenched with $250 \mathrm{mM}$ glycine for 5 minutes at room temperature, and cells were collected in PBS. Pelleted cells were processed for ChIP and analyzed for AR recruitment as previously described (60).

LNCaP-AR F876L xenograft assay. Male NSG (NOD.Cg-Prkdc ${ }^{\text {SCID }}$ Il2 $\mathrm{rg}^{\mathrm{tm} 1 \mathrm{Wil}} / \mathrm{SzJ}$ ) mice (140 mice; obtained from the Duke University breeding colony) were castrated 10 days prior to s.c. injection of $3 \times 10^{6}$ LNCaP-F876L cells (1:1 with Matrigel; BD Biosciences) into the flank. Two days prior to the injection of cells, testosterone-release pellets (12.5 mg/90 day pellet; Innovative Research of America) were implanted s.c. into 60 of the prepared mice. Tumor growth was measured 3 times weekly by caliper [tumor volume $=\left(\mathrm{A}^{2} \times \mathrm{B}\right) / 2$, where $\mathrm{A}$
$<\mathrm{B}$ ]. When tumor volume reached approximately $0.15 \mathrm{~cm}^{3}$, the mice were randomized $(n=9-13)$ to 28 days of oral gavage with vehicle ( $1 \%$ carboxymethylcellulose, $0.1 \%$ Tween 80 , and $5 \%$ DMSO bid); enzalutamide (30 mg/kg qd, vehicle qd); seviteronel (100 mg/kg bid); or abiraterone $(100 \mathrm{mg} / \mathrm{kg}$ bid). Statistical analysis of in vivo data was performed with GraphPad Prism, version 6.0 (GraphPad Software), using exponential growth analyses, 2-way ANOVA comparisons of tumor growth data, and ANOVA comparisons of seminal vesicle weight.

Statistics. For in vitro studies, the SD and SEM are reported in the figure legends for technical and biological replicates, respectively. Nuclear/ cytoplasmic AR ratios (7-9 biological replicates, each consisting of average values for duplicate wells of each condition) as detected by Cellomics analysis (Figure 3) were subjected to 1-way ANOVA comparison followed by Bonferroni's multiple comparisons test. Statistically similar $(P<0.05)$ groups are indicated by lowercase letters in Figure 5C.

For the LNCaP xenograft efficacy study, using the sample size and power function in JMP statistical software (SAS Institute Inc.), it was estimated that an intended group size of 7 per treatment arm would be required to reliably detect with $80 \%$ confidence a statistically relevant $(P<0.05)$ change of $40 \%$, given the anticipated $10 \%$ variability for the tumor models utilized in these studies $(\alpha=0.05, \mathrm{SD}=0.15$, confidence of 0.8 , standard deviation 0.3 ). These estimates were based on 1-way ANOVA followed by the Student's Newman Keul's test. This group size is in accordance with current literature in the field. Animals were randomized to treatment when their tumor size measured $0.08-0.15 \mathrm{~cm}^{3}$. The animals were allocated to treatment, such that the initial tumor volume average per group was $0.125 \pm 0.01 \mathrm{~cm}^{3}$. The final group size for analysis of each treatment arm was as follows: vehicle $(N=6)$, seviteronel $15 \mathrm{mg} / \mathrm{kg}(N=7), 50 \mathrm{mg} / \mathrm{kg}(N=5)$, and $100 \mathrm{mg} / \mathrm{kg}(N=6)$. Two animals (weighing $50 \mathrm{mg} / \mathrm{kg}$ ) died prior to the conclusion of the study and were therefore excluded from the presented data and from poststudy statistical analyses. All other animals were included. The investigator and personnel were not blinded during these studies. The data were subjected to exponential growth-curve analysis constrained to share an initial value and to 2-way ANOVA analysis followed by Bonferroni's multiple comparisons test. Significant differences as compared with the vehicle-treated control group $(P<0.05)$ were detected only for seviteronel at a dose of $100 \mathrm{mg} / \mathrm{kg}$ (days 14-28).

For the LNCaP-AR-F876L xenograft study, using the sample size and power function in JMP statistical software (SAS Institute Inc.), it was estimated that a group size of $N=13$ per treatment arm would be required to reliably detect a statistically relevant $(P<0.05) 25 \%$ change with $80 \%$ confidence, given the anticipated $15 \%$ variability for the tumor models utilized in these studies $(\alpha=0.05, \mathrm{SD}=0.15$, confidence of 0.8 , and s/delta of 0.25). This estimate is based on 1-way ANOVA followed by the Student's Newman Keul's test. This group size is in accordance with current literature in the field. Animals were randomized to treatment when their tumor volume measured $0.12-0.17 \mathrm{~cm}^{3}$. Animals were allocated to treatment, such that the initial tumor volume average per group was $0.15 \pm 0.015 \mathrm{~cm}^{3}$. The group size for each castration treatment arm (no testosterone) was as follows: vehicle $(N=13)$, enzalutamide $(N=13)$, seviteronell $(N=12)$, and abiraterone $(N=13)$. The group size for each castration plus testosterone treatment arm was as follows: vehicle $(N=12)$, enzalutamide $(N=10)$, seviteronell $(N=9)$, and abiraterone $(N=12)$. Eleven animals (distributed across all treatment groups) died as a result of technical error in oral gavage prior to the conclusion of the study; these animals were therefore excluded from the presented data 
and from post-study statistical analyses. All other animals were included. The investigator and personnel were not blinded during this study. The average tumor volume and SEM for each group over 28 days of dosing are presented in Figure 7. These data were subjected to exponential growth-curve analysis constrained to share an initial value and to 2-way ANOVA analysis followed by Bonferroni's multiple comparisons test. Significant differences as compared with the vehicle-treated control group $(P<0.05)$ were detected for seviteronel (days 9-28) and abiraterone (days 11-28) treatment, regardless of testosterone treatment. Enzalutamide treatment was statistically similar to the vehicle control throughout both arms of the study. The groups showed equivalent variance (10\%-15\% with normal distribution) throughout all time points, justifying the statistical analyses that were selected.

For LNCaP xenograft pharmacodynamics study, the fold-change in the expression of AR target genes was plotted by grouped analysis (GraphPad Prism, version 6.0) and evaluated by an unpaired nonparametric $t$ test using 2-tailed analysis of significance values.
Study approval. All animal procedures were approved by the IACUC of Duke University.

\section{Author contributions}

DPM, WDF, WRM, DKP, and JDN designed research. JDN, SJE, JGB, DBS, SEW, SP, HMA, JRE, RMB, AY, KJA, JPS, SAL, and DKP performed experiments and analyzed data. JDN, SJE, and DPM authored the manuscript.

\section{Acknowledgments}

This work was supported by a research grant from Innocrin Pharmaceuticals Inc.

Address correspondence to: Donald P. McDonnell, Duke University Medical School of Medicine, Research Drive, LSRC BLDG, Durham, North Carolina 27710, USA. Phone: 919.684.6035; E-mail: donald.mcdonnell@duke.edu.
1. Siegel RL, Miller KD, Jemal A. Cancer statistics, 2015. CA Cancer JClin. 2015;65(1):5-29.

2. Wong YN, Ferraldeschi R, Attard G, de Bono J. Evolution of androgen receptor targeted therapy for advanced prostate cancer. Nat Rev Clin Oncol. 2014;11(6):365-376.

3. Ryan CJ, et al. Abiraterone in metastatic prostate cancer without previous chemotherapy. N Engl JMed. 2013;368(2):138-148.

4. Chen $\mathrm{CD}$, et al. Molecular determinants of resistance to antiandrogen therapy. Nat Med. 2004;10(1):33-39.

5. Locke JA, et al. Androgen levels increase by intratumoral de novo steroidogenesis during progression of castration-resistant prostate cancer. Cancer Res. 2008;68(15):6407-6415.

6. Taplin ME, et al. Mutation of the androgen-receptor gene in metastatic androgen-independent prostate cancer. N EnglJMed.1995;332(21):1393-1398.

7. Wozney JL, Antonarakis ES. Growth factor and signaling pathways and their relevance to prostate cancer therapeutics. Cancer Metastasis Rev. 2014;33(2-3):581-594.

8. Beer TM, et al. Enzalutamide in metastatic prostate cancer before chemotherapy. $N$ Engl JMed. 2014;371(5):424-433.

9. de Bono JS, et al. Abiraterone and increased survival in metastatic prostate cancer. $N$ Engl J Med. 2011;364(21):1995-2005.

10. Scher HI, et al. Increased survival with enzalutamide in prostate cancer after chemotherapy. N EnglJMed. 2012;367(13):1187-1197.

11. Tran C, et al. Development of a second-generation antiandrogen for treatment of advanced prostate cancer. Science. 2009;324(5928):787-790.

12. Yin L, Hu Q. CYP17 inhibitors--abiraterone, C17,20-lyase inhibitors and multi-targeting agents. Nat Rev Urol. 2014;11(1):32-42.

13. Yoshimoto FK, Auchus RJ. The diverse chemistry of cytochrome P450 17A1 (P450c17, CYP17A1). J Steroid Biochem Mol Biol. 2015;151:52-65.

14. Barrie SE, Potter GA, Goddard PM, Haynes BP, Dowsett M, Jarman M. Pharmacology of novel steroidal inhibitors of cytochrome P450(17) alpha (17 alpha-hydroxylase/C17-20 lyase).
J Steroid Biochem Mol Biol. 1994;50(5-6):267-273.

15. Attard G, et al. Phase I clinical trial of a selective inhibitor of CYP17, abiraterone acetate, confirms that castration-resistant prostate cancer commonly remains hormone driven. JClin Oncol. 2008;26(28):4563-4571.

16. Handratta VD, et al. Novel C-17-heteroaryl steroidal CYP17 inhibitors/antiandrogens: synthesis, in vitro biological activity, pharmacokinetics, and antitumor activity in the LAPC4 human prostate cancer xenograft model. JMed Chem. 2005;48(8):2972-2984.

17. Kaku T, et al. Discovery of orteronel (TAK-700), a naphthylmethylimidazole derivative, as a highly selective 17,20-lyase inhibitor with potential utility in the treatment of prostate cancer. Bioorg Med Chem. 2011;19(21):6383-6399.

18. Rafferty SW, Eisner JR, Moore WR, Schotzinger RJ, Hoekstra WJ. Highly-selective 4-(1,2,3triazole)-based P450c17a 17,20-lyase inhibitors. Bioorg Med Chem Lett. 2014;24(11):2444-2447.

19. Antonarakis ES, et al. AR-V7 and resistance to enzalutamide and abiraterone in prostate cancer. N EnglJ Med. 2014;371(11):1028-1038.

20. Arora VK, et al. Glucocorticoid receptor confers resistance to antiandrogens by bypassing androgen receptor blockade. Cell. 2013;155(6):1309-1322.

21. Azad AA, et al. Androgen Receptor Gene Aberrations in Circulating Cell-Free DNA: Biomarkers of Therapeutic Resistance in Castration-Resistant Prostate Cancer. Clin Cancer Res. 2015;21(10):2315-2324.

22. Robinson $\mathrm{D}$, et al. Integrative clinical genomics of advanced prostate cancer. Cell. 2015;161(5):1215-1228.

23. Beltran $\mathrm{H}$, et al. Targeted next-generation sequencing of advanced prostate cancer identifies potential therapeutic targets and disease heterogeneity. Eur Urol. 2013;63(5):920-926.

24. Joseph JD, et al. A clinically relevant androgen receptor mutation confers resistance to secondgeneration antiandrogens enzalutamide and ARN-509. Cancer Discov. 2013;3(9):1020-1029.

25. Korpal M, et al. An F876L mutation in androgen receptor confers genetic and phenotypic resistance to MDV3100 (enzalutamide). Cancer Dis- cov. 2013;3(9):1030-1043.

26. Taplin ME, et al. Androgen receptor mutations in androgen-independent prostate cancer: Cancer and Leukemia Group B Study 9663. JClin Oncol. 2003;21(14):2673-2678.

27. Yoshida T, et al. Antiandrogen bicalutamide promotes tumor growth in a novel androgendependent prostate cancer xenograft model derived from a bicalutamide-treated patient. Cancer Res. 2005;65(21):9611-9616.

28. Carreira S, et al. Tumor clone dynamics in lethal prostate cancer. Sci Transl Med. 2014;6(254):254ra125.

29. Chen EJ, et al. Abiraterone treatment in castration-resistant prostate cancer selects for progesterone responsive mutant androgen receptors. Clin Cancer Res. 2015;21(6):1273-1280.

30. Kwegyir-Afful AK, Ramalingam S, Purushottamachar P, Ramamurthy VP, Njar VC. Galeterone and VNPT55 induce proteasomal degradation of AR/AR-V7, induce significant apoptosis via cytochrome $c$ release and suppress growth of castration resistant prostate cancer xenografts in vivo. Oncotarget. 2015;6(29):27440-27460.

31. Soifer HS, et al. Direct regulation of androgen receptor activity by potent CYP17 inhibitors in prostate cancer cells. J Biol Chem. 2012;287(6):3777-3787.

32. Vasaitis T, et al. Androgen receptor inactivation contributes to antitumor efficacy of 17 \{alpha\}hydroxylase/17,20-lyase inhibitor 3betahydroxy-17-(1H-benzimidazole-1-yl)androsta5,16-diene in prostate cancer. Mol Cancer Ther 2008;7(8):2348-2357.

33. Yu Z, Cai C, Gao S, Simon NI, Shen HC, Balk SP. Galeterone prevents androgen receptor binding to chromatin and enhances degradation of mutant androgen receptor. Clin Cancer Res. 2014;20(15):4075-4085.

34. Li Z, et al. Conversion of abiraterone to D4A drives anti-tumour activity in prostate cancer. Nature. 2015;523(7560):347-351.

35. Richards J, et al. Interactions of abiraterone, eplerenone, and prednisolone with wild-type and mutant androgen receptor: a rationale for increas- 
ing abiraterone exposure or combining with MDV3100. Cancer Res. 2012;72(9):2176-2182.

36. Toren PJ, et al. Anticancer activity of a novel selective CYP17A1 inhibitor in preclinical models of castrate-resistant prostate cancer. Mol Cancer Ther. 2015;14(1):59-69.

37. Maity SN, et al. Targeting of CYP17A1 Lyase by VT-464 Inhibits Adrenal and Intratumoral Androgen Biosynthesis and Tumor Growth of Castration Resistant Prostate Cancer. Sci Rep. 2016;6:35354.

38. Small EJ, et al. Antiandrogen withdrawal alone or in combination with ketoconazole in androgenindependent prostate cancer patients: a phase III trial (CALGB 9583). JClin Oncol. 2004;22(6):1025-1033.

39. Taplin ME, et al. Phase II study of androgen synthesis inhibition with ketoconazole, hydrocortisone, and dutasteride in asymptomatic castration-resistant prostate cancer. Clin Cancer Res. 2009;15(22):7099-7105.

40. Vanaja DK, Mitchell SH, Toft DO, Young CY. Effect of geldanamycin on androgen receptor function and stability. Cell Stress Chaperones. 2002;7(1):55-64.

41. Norris JD, et al. Differential presentation of protein interaction surfaces on the androgen receptor defines the pharmacological actions of bound ligands. Chem Biol. 2009;16(4):452-460.

42. Pollock JA, et al. Inhibiting androgen receptor nuclear entry in castration-resistant prostate cancer. Nat Chem Biol. 2016;12(10):795-801.

43. Nguyen TV, Yao M, Pike CJ. Flutamide and cyproterone acetate exert agonist effects: induction of androgen receptor-dependent neuroprotection. Endocrinology. 2007;148(6):2936-2943.

44. Dijkman GA, Janknegt RA, De Reijke TM, Debruyne FM. Long-term efficacy and safety of nilutamide plus castration in advanced prostate cancer, and the significance of early prostate specific antigen normalization. International Anandron Study Group. J Urol. 1997;158(1):160-163.

45. Song LN, Coghlan M, Gelmann EP. Antiandrogen effects of mifepristone on coactivator and corepressor interactions with the androgen receptor. Mol Endocrinol. 2004;18(1):70-85.

46. Bohl CE, Wu Z, Miller DD, Bell CE, Dalton JT. Crystal structure of the T877A human androgen receptor ligand-binding domain complexed to cyproterone acetate provides insight for ligand-induced conformational changes and structure-based drug design. J Biol Chem. 2007;282(18):13648-13655.

47. Joseph JD, et al. Inhibition of prostate cancer cell growth by second-site androgen receptor antagonists. Proc Natl Acad Sci USA. 2009;106(29):12178-12183.

48. Dalton JT, et al. The selective androgen receptor modulator GTx-024 (enobosarm) improves lean body mass and physical function in healthy elderly men and postmenopausal women: results of a double-blind, placebo-controlled phase II trial. JCachexia Sarcopenia Muscle. 2011;2(3):153-161.

49. Cutress ML, Whitaker HC, Mills IG, Stewart M, Neal DE. Structural basis for the nuclear import of the human androgen receptor. J Cell Sci. 2008;121(Pt 7):957-968.

50. Ferraldeschi R, Welti J, Luo J, Attard G, de Bono JS. Targeting the androgen receptor pathway in castration-resistant prostate cancer: progresses and prospects. Oncogene. 2015;34(14):1745-1757.

51. de Bono JS, et al. The oral CYP17-Lyase (L) inhibitor VT-464 in patients with CRPC [abstract 187]. JClin Oncol. 2015;33(suppl 7):187.

52. Xtandi ${ }^{\circledast}$ [prescribing information]. Astellas Pharma US, Inc. https://www.accessdata.fda. gov/drugsatfda_docs/label/2012/203415lbl.pdf. Accessed April 20, 2017.
53. Zytiga ${ }^{\circledR}$ [prescribing information]. Janssen Biotech, Inc. https://www.zytiga.com/shared/ product/zytiga/zytiga-prescribing-information. pdf. Accessed April 20, 2017.

54. Williams G, et al. Objective responses to ketoconazole therapy in patients with relapsed progressive prostatic cancer. Br JUrol. 1986;58(1):45-51.

55. Loriot $\mathrm{Y}$, et al. Antitumour activity of abiraterone acetate against metastatic castration-resistant prostate cancer progressing after docetaxel and enzalutamide (MDV3100). Ann Oncol. 2013;24(7):1807-1812.

56. Noonan KL, North S, Bitting RL, Armstrong AJ, Ellard SL, Chi KN. Clinical activity of abiraterone acetate in patients with metastatic castration-resistant prostate cancer progressing after enzalutamide. Ann Oncol. 2013;24(7):1802-1807.

57. Kramer WG, Vince B, McGarry C. Comparison of the pharmacokinetics (PK) of galeterone nove oral formulations [abstract e16075]. J Clin Oncol. 2013;31(15 suppl):e16075.

58. Fizazi K, et al. Phase III, randomized, doubleblind, multicenter trial comparing orteronel (TAK-700) plus prednisone with placebo plus prednisone in patients with metastatic castration-resistant prostate cancer that has progressed during or after docetaxelbased therapy: ELM-PC 5. JClin Oncol. 2015;33(7):723-731.

59. Saad F, et al. Orteronel plus prednisone in patients with chemotherapy-naive metastatic castration-resistant prostate cancer (ELM-PC 4): a double-blind, multicentre, phase 3 , randomised, placebo-controlled trial. Lancet Oncol. 2015;16(3):338-348.

60. Norris JD, et al. The homeodomain protein HOXB13 regulates the cellular response to androgens. Mol Cell. 2009;36(3):405-416. 